\title{
(6) OPEN ACCESS \\ Supporting adherence for people starting a new medication for a long-term condition through community pharmacies: a pragmatic randomised controlled trial of the New Medicine Service
}

\author{
Rachel Ann Elliott, ${ }^{1,2}$ Matthew J Boyd, ${ }^{2}$ Nde-Eshimuni Salema, ${ }^{2}$ \\ James Davies, ${ }^{3}$ Nicholas Barber, ${ }^{4}$ Rajnikant Laxmishanker Mehta, ${ }^{5}$ \\ Lukasz Tanajewski, ${ }^{2,6}$ Justin Waring, ${ }^{7}$ Asam Latif, ${ }^{2}$ \\ Georgios Gkountouras, ${ }^{2,6}$ A J Avery, ${ }^{8}$ Antony Chuter, ${ }^{1}$ Christopher Craig $^{2}$
}

- Additional material is published online only. To view please visit the journal online (http://dx.doi.org/10.1136/bmjqs2015-004400).

For numbered affiliations see end of article.

\section{Correspondence to} Professor Rachel Ann Elliott, School of Pharmacy, University of Nottingham, University Park, Nottingham NG7 2RD, UK; rachel.elliott@nottingham.ac.uk

Received 15 May 2015 Revised 21 September 2015 Accepted 25 September 2015 Published Online First 8 December 2015

\section{SLinked}

- http://dx.doi.org/10.1136/ bmjqs-2015-004670 - http://dx.doi.org/10.1136/ bmjqs-2015-004886

CrossMark

To cite: Elliott RA, Boyd MJ, Salema N-E, et al. BMJ Qual Saf 2016:25:747-758.

\begin{abstract}
Objective To examine the effectiveness of the New Medicine Service (NMS), a national community pharmacy service to support medicines-taking in people starting a new medicine for a long-term condition, compared with normal practice.
\end{abstract}

Methods Pragmatic patient-level parallel randomised controlled trial, in 46 community pharmacies in England. Patients 1:1 block randomisation stratified by drug/disease group within each pharmacy. 504 participants (NMS: 251) aged 14 years and over, identified in the pharmacy on presentation of a prescription for asthma/chronic obstructive pulmonary disease, hypertension, type 2 diabetes or an anticoagulant/antiplatelet agent. NMS intervention: One consultation 7-14 days after presentation of prescription followed by another 14-21 days thereafter to identify problems with treatment and provide support if needed. Controls received normal practice. Adherence, defined as missing no doses without the advice of a medical professional in the previous 7 days, was assessed through patient self-report at 10 weeks. Intention-to-treat analysis was employed, with outcome adjusted for recruiting pharmacy, NMS disease category, age, sex and medication count. Cost to the National Health Service (NHS) was collected.

Results At 10 weeks, 53 patients had withdrawn and 443 (85\%) patients were contacted successfully by telephone. In the unadjusted analysis of 378 patients still taking the initial medicine, $61 \%$ (95\% Cl 54\% to $67 \%$ ) and $71 \%$ (95\% Cl 64\% to $77 \%$ ) patients were adherent in the normal practice and NMS arms, respectively ( $p=0.04$ for difference). In the adjusted intentionto-treat analysis, the OR for increased adherence was $1.67(95 \% \mathrm{Cl} 1.06$ to $2.62 ; \mathrm{p}=0.027)$ in favour of the NMS arm. There was a general trend to reduced NHS costs, albeit, statistically nonsignificant, for the NMS intervention: saving $f 21$ ( $95 \% \mathrm{Cl}-f 59$ to $f 100, p=0.128$ ) per patient. Conclusions The NMS significantly increased the proportion of patients adhering to their new medicine by about $10 \%$, compared with normal practice.

Trial registration numbers ClinicalTrials.gov trial reference number NCT01635361 (http:// clinicaltrials.gov/ct2/show/NCT01635361). Current Controlled trials: trial reference number ISRCTN 23560818 (http://www.controlled-trials. com/ISRCTN23560818/; DOI 10.1186/

ISRCTN23560818). UK Clinical Research Network (UKCRN) study 12494 (http://public.ukcrn.org.uk/ Search/StudyDetail.aspx?StudyID=12494).

\section{INTRODUCTION}

Adherence to medication is defined as the extent to which individuals take their medication as prescribed. ${ }^{1}$ Suboptimal medicines adherence has been reported in many illnesses such as chronic obstructive pulmonary disease $(33 \%))^{2}$ asthma $(67 \%)^{3}$ and schizophrenia 52\%. Adherence reduces with time from initial prescription. In depression, adherence 
was reported to drop from $95.5 \%$ to $52.6 \%$ over a 1-month period. ${ }^{5}$ Low adherence increases risk of hospitalisations and premature mortality. ${ }^{6-8}$ Worldwide, medicines non-adherence constitutes 57\% of the estimated US $\$ 500$ billion wasted from suboptimal medicines use. ${ }^{9}$ The annual economic impact of non-adherence to five key conditions (asthma, type 2 diabetes, high cholesterol/coronary heart disease, hypertension and schizophrenia) to the English National Health Service (NHS England) has been estimated at over $£ 930$ million. ${ }^{10}$ Annual savings of $£ 500$ million could be realised if adherence were improved.

Many interventions to improve medicines adherence are complex, multifaceted and not grounded in theory about the reasons why people are non-adherent. ${ }^{11}$ Effective interventions focus on self-management, promoting sustained behaviour change. ${ }^{12}$ This may involve more acceptable regimens, removing financial barriers, changing misguided beliefs about the disease and medicines, empowering self-management, improving patientprovider relationships and involving the patient's 'social world'. Overemphasis on the educational needs of patients only is a weakness of many interventions.

When patients receive a new (to them) medicine for a long-term condition, they often experience problems which lead to a proportion becoming non-adherent. ${ }^{13}$ Barber developed an intervention with a theoretical basis in the self-regulatory model, ${ }^{14}$ grounded in the patient's perspective and designed to elicit patients' experiences with, and concerns about, their new medicine. This was used as a starting point for the pharmacists to meet each individual's specific needs with information and advice. This theory-based pharmacist-led intervention significantly reduced reported problems and non-adherence in a costeffective manner. ${ }^{15} 16$

The New Medicine Service (NMS) in England is the first national service designed to improve medicines adherence $^{17}$ and is offered by community pharmacists to people starting a new medicine for asthma/chronic obstructive pulmonary disease, type 2 diabetes, hypertension or antiplatelet/anticoagulant treatment. ${ }^{18}$ The design is based on the initial work described above, but the original intervention targeted a wider range of patients whereas the NMS has four specified groups. The original intervention was delivered via a centralised telephone service, whereas NMS is delivered by the pharmacist providing the medicine, either face-to-face or over the telephone. Advanced services are commissioned nationally via the NHS community pharmacy contractual framework and can be delivered following appropriate accreditations. NMS was implemented as an advanced service in October 2011. Community pharmacies in England have to be accredited to provide NMS and are given guidance on how to conduct the intervention and follow-up consultations. ${ }^{18}$ This guidance provides a topic guide for pharmacists and an NMS interview schedule. They are remunerated for each episode of care. Of 11495 community pharmacies in England 10553 (91.2\%) had claimed for at least one NMS episode up to January 2014. ${ }^{19}$ The aim of this study was to evaluate the effectiveness of the NMS compared with normal practice in changing medicines-taking behaviour, using a robust, pragmatic randomised controlled trial (RCT) in community pharmacies in England.

\section{METHODS}

\section{Study design}

The study is reported according to Consolidated Standards of Reporting Trials (CONSORT) criteria. ${ }^{20}$ The study was a patient-level multicentre, pragmatic RCT involving a parallel group design. The study was overseen by an advisory group. The protocol has been published. ${ }^{21} 22$

\section{Study setting}

Community pharmacies in East Midlands and South Yorkshire and Greater London accredited to provide the NMS were eligible to take part, an area with approximately 870 pharmacies. Pharmacy selection took into account pharmacy ownership (independent, small, medium and large multiples), proximity to general practice (GP), setting (rural vs urban) and economic deprivation.

\section{Study participants}

Patients were able to take part in the RCT if they were eligible for NMS, community-dwelling, aged 14 years or over, able to consent to the NMS and the study and willing to provide written consent (parental consent for 14-year-olds and 15 year-olds).

\section{Recruitment}

A pragmatic approach was used to include pharmacies covering the range of characteristics listed above, by inviting pharmacies from all groups to participate. No further training on delivering the intervention or normal practice was provided to prevent alteration of the pragmatic status of the study. Individual pharmacists within the pharmacy had the option to participate in the study.

Patients were recruited within community pharmacies by the study pharmacists (see figure 2). Consenting to the NMS was a prerequisite for a patient being invited to the study. It was explained that if they joined the RCT, they could be randomised to normal practice, and not receive NMS. Patients were given as long as they needed to read the study information and ask questions. The normal $24 \mathrm{~h}$ grace period for consent was not appropriate as the intervention needed to be scheduled while the patient was in the pharmacy. Therefore, patients received an additional welcome call from the researcher to answer subsequent questions and patients were also reminded that they could withdraw. 


\section{Randomisation and blinding}

Patients were randomised into one of the two study arms stratified by drug/disease group within each pharmacy using Statistical Analysis Software. ${ }^{23}$ Block randomisation was used within each pharmacy to avoid allocation imbalances. Sequentially numbered tamper-proof opaque sealed envelopes were used to conceal sequence allocation. Separate randomisation sequences were produced for patients 16 years and over and for patients aged 14 years and 15 years, due to the age-specific motivators for adherence in this latter group. ${ }^{24}$ Researchers collecting data were blinded to study arm except in the case of accidental disclosure by study participants or when inviting a participant to the qualitative arm of the study. The qualitative work is available in the main report. $^{22}$

\section{NMS intervention}

NMS begins with the patient's initial presentation with a prescription for a new medicine in a community pharmacy. Patients can be referred to the service by their prescriber (GP or nurse), can self-refer or the pharmacist can invite the patient to use the service. The NMS intervention itself is relatively rapid and comprises two parts, named 'intervention' and 'follow-up' by the commissioners. The pharmacist invites the patient to a one-to-one consultation 714 days later (the 'intervention') with a 'follow-up' 14-21 days after that, meaning the whole episode should be complete within a maximum of 5 weeks. These are the points in the service where the pharmacist would ask about adherence and experiences with the medicine. Primary outcomes were collected by researchers at 10 weeks from initial prescription presentation in both study arms.
The primary aim of the intervention, which can be face-to-face or telephone-based, (in this study, all follow-up was via telephone) is the patient-centred identification of any problems with the treatment (including adverse drug reactions) and support or action needed (figure 1). Action may include referring the patient back their prescriber to review their medication.

\section{Normal practice}

Normal practice was the pharmacist's usual advice when presented with a prescription for a new medicine for a long-term condition. No follow-up is offered to this group of patients. The episode ceases either until the next prescription is presented or further assistance is sought by the patient.

\section{Outcomes}

Primary outcome

The primary outcome is self-reported adherence at 10 weeks from the initiation of the intervention (see table 1). Patients were followed up at 10 weeks, expected to be the minimum time required to demonstrate any behavioural changes from the intervention. ${ }^{15}$

Patients were contacted by telephone and asked about adherence behaviour using the question: "People often miss taking doses of their medicines, for a wide range of reasons. Have you missed any doses of your new medicine, or changed when you take it? (Prompt: when did you last miss a dose?)". ${ }^{25}$ This is the adherence question asked by pharmacists during the NMS intervention and follow-up.

The patient was defined as non-adherent if any doses were missed without the advice of a medical professional in the previous 7 days.

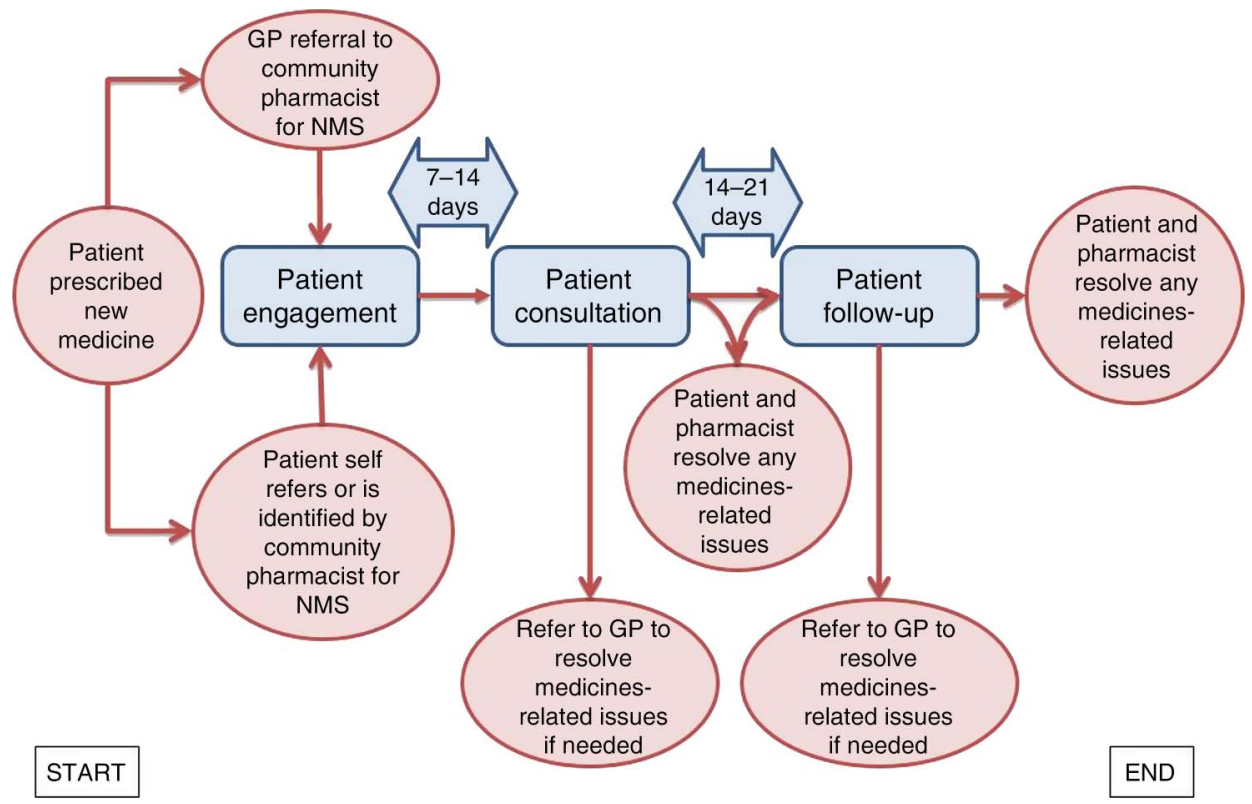

Figure 1 New Medicine Service intervention. 


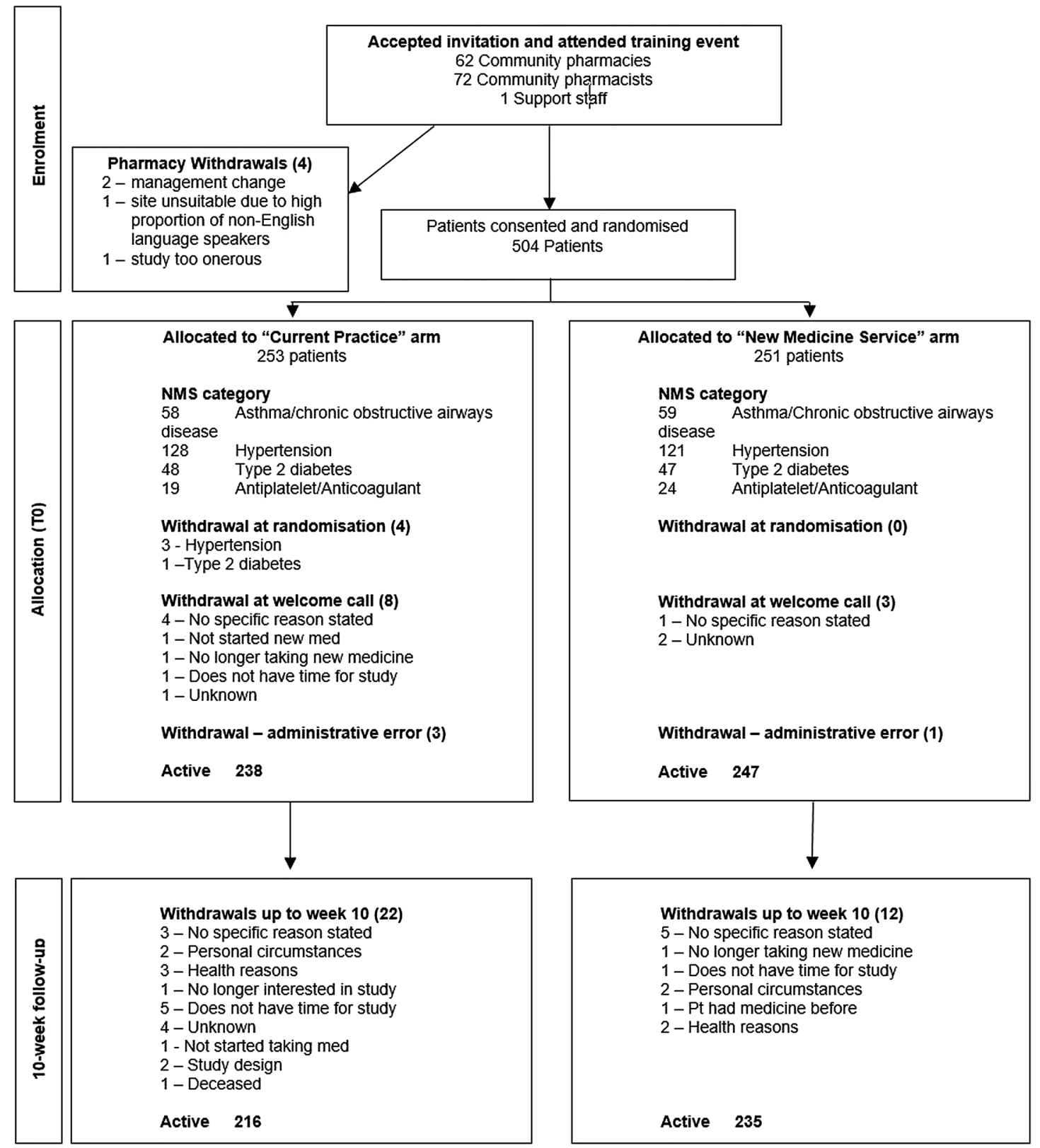

Figure 2 Overview of pharmacy and patient recruitment (CONSORT). 'Active' patients indicates how many patients are contributing data to the study at each time point, by arm. As part of the study pharmacies were asked to provide a 4-weekly return indicating the number of patients approached, but who declined. Despite significant efforts by the study team throughout, only $25 \%$ of these were returned, meaning an accurate indication of patients approached was not possible. Of the 3694 week recording periods over the 61 pharmacies, data were received for 94 of these periods. In the remaining periods either pro forma were not returned or returned not completed. Across the 94 periods, 470 declines were recorded. Declines by pharmacy ranged from 1 to 150. It was therefore not possible to report the number of patients approached. Patients who did not wish to receive the New Medicine Service (NMS) service were given a short questionnaire to complete and return to the study team. There were 11 responses from 117 questionnaires issued with the majority (7/11) stating they did not see the need as their general practice would be reviewing them in due course.

The Morisky Eight Item Medication Adherence Scale (MMAS-8), validated in hypertension, was used to support the primary outcome measure, and collected via self-completion postal questionnaire (expected to result in a lower response rate). ${ }^{26}$

The main intention of the NMS intervention is to enhance adherence to the newly prescribed medicine. Situations will inevitably present, such as experiencing severe side effects, where it would be inappropriate for a patient to continue taking their prescribed new medicine. Therefore, the medicine can also be stopped or changed appropriately by the prescriber, with or without referral from the pharmacist during the NMS intervention. Patients' medicines may also be stopped or changed appropriately in the normal practice arm. When a patient's new medicine was substituted by another medicine this patient was classed as having their new medicine changed. On the other 
Table 1 Summary of outcome measures collected at 10 weeks

\begin{tabular}{|c|c|}
\hline Outcome measure & Method of recording \\
\hline $\begin{array}{l}\text { Adherence } \\
\text { NMS question }\end{array}$ & Telephone interview* \\
\hline $\begin{array}{l}\text { Adherence } \\
\text { Morisky's Medication Adherence Scale } \\
8 \text {-item version (MMAS-8) }{ }^{26} \dagger\end{array}$ & $\begin{array}{l}\text { Self-completed postal } \\
\text { questionnaire } \neq\end{array}$ \\
\hline $\begin{array}{l}\text { Medicines stopped or changed by the } \\
\text { prescriber }\end{array}$ & Telephone interview* \\
\hline $\begin{array}{l}\text { Health status } \\
\text { EuroQol-5 Dimension-3 Level Instrument } \\
\left(\text { EQ-5D-3L) }{ }^{27}\right.\end{array}$ & $\begin{array}{l}\text { Self-completed postal } \\
\text { questionnairef }\end{array}$ \\
\hline $\begin{array}{l}\text { Medicines understanding } \\
\text { Beliefs About Medicines Questionnaire } \\
\text { (BMQ) }{ }^{28}\end{array}$ & $\begin{array}{l}\text { Self-completed postal } \\
\text { questionnairef }\end{array}$ \\
\hline Healthcare resource use & Self-completed diary§ \\
\hline
\end{tabular}

*Participants were asked to specify optimal contact times at registration. Up to seven attempts were made for each time point if unsuccessful. tUse of the MMAS is protected by US copyright laws. Permission for use is required. A license agreement is available from: Donald E Morisky, SCD, SCM, MSPH, Professor, Department of Community Health Sciences, UCLA School of Public Health, 650 Charles E. Young Drive South, Los Angeles, CA 90095-1772.

$\ddagger$ Questionnaires were issued prior to telephone interviews. Return status was checked during the telephone interview and actioned as necessary. $\S$ Interactions with primary, secondary, social care and allied health professionals were recorded on an episodic basis. Wasted medicines were not recorded.

NMS, New Medicine Service.

hand, if a prescriber had directed that the patient stop their new medicine this was classified as stopped new medicine. A composite measure of success is the patient either being adherent to the first medicine, or it being appropriately stopped or changed. The outcome is reported as proportion of patients adherent to newly prescribed medicine, or appropriately stopped or changed by the prescriber (composite outcome $=$ adherence plus stopped/changed).

Composite outcomes were constructed for the NMS question and the MMAS- 8 by including those patients adherent to the initial medicine and those whose medicines had been stopped or changed appropriately by the prescriber:

- 'Composite NMS' (Patients successfully managed composite outcome using NMS question): adherent plus (stopped or changed appropriately by the prescriber);

- 'Composite MMAS-8' (Patients successfully managed composite outcome using MMAS-8): adherent plus (stopped or changed appropriately by the prescriber).

Other outcomes

Health status, medicines understanding and healthcare resource use were also recorded.

\section{Costs}

Resource use associated with the interventions (time spent, costs of telephone calls) was recorded for each patient. Subsequent NHS contact or patient costs were recorded by the patient in diaries for 10 weeks after the intervention. Resource use data were combined with NHS reference costs ${ }^{29}$ and Personal Social Services Research Unit costs ${ }^{30}$ to derive total costs per patient. Unit costs are summarised in online supplementary appendix tables 1 and 2. Comparisons between treatment arms were made using a twosample $t$ test on the original data set, or on a bootstrapped data set, depending on the normality of the distribution of costs. ${ }^{31}$

\section{Sample size}

Estimation of sample size was based on the effect observed by the intervention in the original work. ${ }^{15}$ Prevalence of non-adherence behaviour measured by the NMS question at 10 weeks follow-up (primary outcome) was expected to fall from $20 \%$ to $10 \%$. A sample size of 200 patients/arm was required to detect this change with $80 \%$ power, $5 \%$ significance level (two-tailed). Up to 100 patients were expected to be lost to follow-up, withdraw from the study or change/ stop medication. To maintain study power 250 patients/arm was the planned sample size (table 2).

Starting new medication for one of these long-term conditions is not that common an event per pharmacy. Pharmacies initiating at least two NMS consultations/ week were recruited, to provide 52 eligible patients in 6 months. Assuming that $50 \%$ of eligible patients consented, approximately 20 pharmacies were needed. There was lower than predicted NMS uptake within study pharmacies either because eligible patients were not presenting, or because the pharmacist could not identify that the prescription was for a new medication, due to lack of access to patient medical records. In 2013 the number of recruiting pharmacies was expanded to 61, of which 46 ultimately provided patients. Recruitment was stopped once the required sample size was reached.

\section{Statistical analysis}

Intention-to-treat (ITT) analysis was used. ${ }^{32} \quad 33$ Adherence rates were analysed using the $\chi^{2}$ test or Fisher's exact test. The ITT cohort was defined as all patients within a randomisation arm with measured outcomes, or who had withdrawn from the study.

Simple logistic regression analysis assessed unadjusted effect of NMS on the outcome (Model 1: 'naïve' results). Multilevel logistic regression analysis adjusted effect size for clustering of data and confounding by disease, age, sex and medication count (Model 2). Two levels were defined in the multilevel analysis: (1) Patient, (2) Pharmacy.

Full application of ITT analysis can only be performed where there is complete outcome data for all randomised subjects. To include such participants in an analysis, the outcome data were imputed which involves making assumptions about the outcomes in the lost participants. ${ }^{34}{ }^{35}$ Generalised estimating equations $^{36} 37$ techniques took account of correlated outcome data. Multiple imputation by chained 


\section{Original research}

Table 2 Patient characteristics

\begin{tabular}{|c|c|c|c|c|}
\hline Patient characteristics & Normal practice $\mathrm{n}(\%)$ & & New Medicine Service $\mathbf{n}(\%)$ & \\
\hline Total N (\%) & $253(100.0)$ & & $251(100.0)$ & \\
\hline Antiplatelet/anticoagulant $(n=43,8.5 \%)$ & $19(7.5)$ & & $24(9.6)$ & \\
\hline Asthma /COPD ( $n=117,23.2 \%)$ & $58(22.9)$ & & $59(23.5)$ & \\
\hline Hypertension ( $n=249,49.4 \%$ ) & $128(50.6)$ & & $121(48.2)$ & \\
\hline Type 2 diabetes $(n=95,18.8 \%)$ & $48(19.0)$ & & $47(18.7)$ & \\
\hline Female $(n=260,51.6 \%)$ & $135(53.4)$ & & $125(49.8)$ & \\
\hline Male $(n=244,48.4 \%)$ & $118(46.6)$ & & $126(50.2)$ & \\
\hline Age of total cohort (years) (N: Mean (SD)) & 253: $59.3(15.0)$ & & 251: 59.5 (15.3) & \\
\hline Age (female) (years) (N: Mean (SD)) & 135: $58.7(15.4)$ & & 125: $56.8(16.0)$ & \\
\hline Age (male) (years) (N: Mean (SD)) & 118: $60.0(14.6)$ & & 126: $62.2(14.1)$ & \\
\hline $\begin{array}{l}\text { No of NMS eligible new medicine(s) at study } \\
\text { entry }(n(\%))\end{array}$ & Total NMS medicines: 257 & & Total NMS medicines: 262 & \\
\hline 1 & $249(98.4)$ & & $241(96.0)$ & \\
\hline 2 & $4(1.6)$ & & $9(3.6)$ & \\
\hline 3 & $0(0.0)$ & & $1(0.4)$ & \\
\hline Mean (SD) number of other medicines & $3.6(3.4)$ & & $3.5(3.4)$ & \\
\hline \multicolumn{5}{|c|}{ Most commonly prescribed medicines ( $\%$ medicines prescribed in that disease category) } \\
\hline Antiplatelet/anticoagulant & $\begin{array}{l}\text { Aspirin } \\
\text { Clopidogrel } \\
\text { Dipyridamole } \\
\text { Warfarin }\end{array}$ & $\begin{aligned} 10 & (52.6) \\
7 & (36.8) \\
1 & (5.3) \\
1 & (5.3)\end{aligned}$ & $\begin{array}{l}\text { Aspirin } \\
\text { Clopidogrel } \\
\text { Dipyridamole } \\
\text { Warfarin }\end{array}$ & $\begin{aligned} 11 & (45.8) \\
9 & (37.5) \\
1 & (4.2) \\
3 & (12.5)\end{aligned}$ \\
\hline Asthma/COPD & $\begin{array}{l}\text { Salbutamol } \\
\text { Beclometasone (Clenil) } \\
\text { Budesonide and formoterol (Symbicort) } \\
\text { Tiotropium (Spiriva) } \\
\text { Formoterol and beclometasone (Fostair) }\end{array}$ & $\begin{aligned} 11 & (18.0) \\
7 & (11.5) \\
7 & (11.5) \\
7 & (11.5) \\
6 & (9.8)\end{aligned}$ & $\begin{array}{l}\text { Salbutamol } \\
\text { Beclometasone (Clenil) } \\
\text { Tiotropium (Spiriva) } \\
\text { Fluticasone and salmeterol (Seretide) } \\
\text { Ipratropium }\end{array}$ & $\begin{aligned} 20 & (30.8) \\
12 & (18.5) \\
10 & (15.4) \\
6 & (9.2) \\
5 & (7.7)\end{aligned}$ \\
\hline Hypertension & $\begin{array}{l}\text { Amlodipine } \\
\text { Ramipril } \\
\text { Indapamide } \\
\text { Bisoprolol } \\
\text { Losartan }\end{array}$ & $\begin{array}{l}40(30.8) \\
29(22.3) \\
11(8.5) \\
10(7.7) \\
10(7.7)\end{array}$ & $\begin{array}{l}\text { Amlodipine } \\
\text { Ramipril } \\
\text { Losartan } \\
\text { Bisoprolol } \\
\text { Indapamide }\end{array}$ & $\begin{array}{l}38(30.2) \\
24(19.0) \\
11(8.7) \\
10(7.9) \\
10(7.9)\end{array}$ \\
\hline Type 2 diabetes & $\begin{array}{l}\text { Metformin } \\
\text { Gliclazide } \\
\text { Insulin (various) } \\
\text { Sitagliptin } \\
\text { Saxagliptin }\end{array}$ & $\begin{aligned} 22 & (44.9) \\
11 & (22.4) \\
7 & (14.3) \\
5 & (10.2) \\
2 & (4.1)\end{aligned}$ & $\begin{array}{l}\text { Metformin } \\
\text { Gliclazide } \\
\text { Sitagliptin } \\
\text { Acarbose } \\
\text { Insulin various }\end{array}$ & $\begin{aligned} 25 & (53.2) \\
12 & (25.5) \\
5 & (10.6) \\
1 & (2.1) \\
2 & (4.2)\end{aligned}$ \\
\hline \multicolumn{5}{|c|}{ Economic deprivation based on IMD Score* (Mean (SD)) } \\
\hline Pharmacy study sites & $30.7(14.0)$ & & $31.1(13.6)$ & \\
\hline Study patients & $25.0(15.0)$ & & $24.2(15.3)$ & \\
\hline \multicolumn{5}{|l|}{ Location of pharmacy study site (n (\%) } \\
\hline Derbyshire & $46(18.2)$ & & $55(21.9)$ & \\
\hline South Yorkshire & $35(13.8)$ & & $31(12.4)$ & \\
\hline Leicestershire & $15(5.9)$ & & $10(4.0)$ & \\
\hline Nottinghamshire & $117(46.2)$ & & $114(45.4)$ & \\
\hline Greater London & $40(15.8)$ & & $41(16.3)$ & \\
\hline \multicolumn{5}{|l|}{ Pharmacy ownershipt (n (\%)) } \\
\hline Independent & $65(25.7)$ & & $56(22.3)$ & \\
\hline Large multiple & $63(24.9)$ & & $68(29.1)$ & \\
\hline Small multiple & $122(48.2)$ & & $123(49.0)$ & \\
\hline Supermarket & $3(1.2)$ & & $4(1.6)$ & \\
\hline
\end{tabular}

*Economic Deprivation Index (Score)—Data from the Office of National Statistics was used to ascertain the deprivation index for each pharmacy using the postcode as the lookup reference. ${ }^{41}$ Data were collected for two variables: (1) IMD score and (ii) rank of IMD score. The IMD score is directly proportional to the level of deprivation (higher IMD score; higher level of deprivation) while the IMD rank is inversely proportional to the level of deprivation (lower IMD rank; higher level of deprivation). The Office of National Statistics data records the English deprivation scores as ranging from 0.5 to 87.8 and deprivation rank scores ranging from 1 to 32482 .

tDefinition of large multiples and supermarkets—the 10 largest pharmacy entities in England, Small multiples_pharmacies with six or more branches and Independents-pharmacies with one to five 5 branches. ${ }^{42}$

COPD, chronic obstructive pulmonary disease; IMD, Index of Multiple Deprivation; N, number; NMS, New Medicine Service. 
equations analysis of Model 2 dealt with missing data (Model 3: sensitivity analysis to check the effects of the missing data on the outcome).

Predetermined subgroup analyses ${ }^{38}$ explored whether effect varied by disease, age, gender, pharmacy ownership, pharmacy location, number of other medicines prescribed and deprivation index. Exploratory analyses of secondary outcome measures were also carried out.

Study data (disease, age, gender, ethnicity, number of NMS medicines) were compared with anonymised national records of completed NMS episodes from service inception (1 October 2011) to 2 December 2013. (https://www.pharmoutcomes.org/ pharmoutcomes/, Health Information Exchange, Hampshire).

Statistical analyses were conducted using Statistical Package for the Social Sciences V.20 $0^{39}$ and Stata V.13.0. ${ }^{40}$

\section{Pilot study}

The study was piloted in four pharmacy sites to ensure that training, set-up of the pharmacy to operationalise the study, recruitment methods, study materials and processes were satisfactory before full roll-out to all phase 1 pharmacies. Four patients were recruited as part of the pilot prior to wider roll-out.

\section{RESULTS}

The pilot study lasted from July to September 2012, and no changes were made to the methods prior to the full study from October 2012 to September 2013. Between July 2012 and September 2013, 504 patients were recruited from 46 of the 61 pharmacies (range 1-99 patients).

Researcher blinding was broken 75 times in the course of the study, (42 in the NMS arm and 33 in the normal practice arm) accounting for $14.9 \%$ of recruited patients. Of these, 66 instances were purposeful due to checking eligibility for qualitative arm of the study. The remaining nine were due to either patient or pharmacist accidentally disclosing their study arm at phone call.

The two groups were well matched (figure 2) for patient characteristics (table 2), most commonly prescribed drugs being amlodipine, ramipril and metformin. There was also a similar disease distribution overall and by gender, age and ethnicity to the national data set cohort (see online supplementary appendix table 3).

\section{Effect of NMS on adherence}

Results at Week 10 are shown in table 3. By Week 10, 37 and 16 patients had withdrawn from the normal practice and NMS arms, respectively.

Primary outcome: NMS question

In the unadjusted ITT analysis of 378 patients still taking the initial medicine, 115/190 (60.5\%) and 133/ $188(70.7 \%)(\mathrm{p}=0.037)$ patients were adherent in the normal practice and NMS arms, respectively. Predictions of adherence were calculated on an ITT basis giving an OR (95\% CI) of 1.58 (1.03 to 2.42, $\mathrm{p}=0.037)$, in Model 1. In the adjusted analysis (Model 2), adherence gave an OR (95\% CI) of 1.67 (1.06 to $2.62, \mathrm{p}=0.027$ ), in favour of NMS. In the

Table 3 Reported adherence by patients to their new medicine and intention-to-treat analysis of the intervention as a predictor of adherence at Week 10-frequency counts, unadjusted, adjusted and imputed ORs

\begin{tabular}{|c|c|c|c|c|}
\hline $\begin{array}{l}\mathrm{N}=\text { patients with outcomes } \\
\text { recorded plus withdrawn } \\
\text { patients }\end{array}$ & $\begin{array}{l}\text { Number of adherent } \\
\text { patients/total } \\
\text { responses N (\%), p }\end{array}$ & Model* 1 OR $(95 \% \mathrm{Cl}, \mathrm{p})$ & $\begin{array}{l}\text { Model* }^{*} \text { (Adjusted) } \\
\text { OR }(95 \% \mathrm{Cl}, \mathrm{p})\end{array}$ & $\begin{array}{l}\text { Model* }^{*} \text { (Imputation) } \\
\text { OR }(95 \% \mathrm{Cl}, \mathrm{p})\end{array}$ \\
\hline \multicolumn{5}{|c|}{ Adherence NMS ( $\mathrm{N}=378,126$ responses missing) } \\
\hline Normal practice & $115 / 190(60.5)$ & 1.00 & 1.00 & 1.00 \\
\hline NMS & 133/188 (70.7), 0.037 & $1.58(1.03$ to $2.42,0.037)$ & $1.67(1.06$ to $2.62,0.027)$ & $1.62(1.04$ to $2.53,0.032)$ \\
\hline \multicolumn{5}{|c|}{ Composite NMS (N=443, 61 responses missing) $†$ (adherent+stopped+changed) } \\
\hline Normal practice & $144 / 222(64.9)$ & 1.00 & 1.00 & 1.00 \\
\hline NMS & $165 / 221(74.7), 0.025$ & $1.60(1.06$ to $2.40,0.025)$ & $1.68(1.09$ to $2.58,0.018)$ & $1.64(1.08$ to $2.50,0.021)$ \\
\hline \multicolumn{5}{|c|}{ Adherence MMAS-8 ( $N=267,237$ responses missing) } \\
\hline Normal practice & $85 / 143(59.4)$ & 1.00 & 1.00 & 1.00 \\
\hline NMS & $89 / 124(71.8), 0.035$ & $1.74(1.04$ to $2.90,0.036)$ & $1.88(1.06$ to $3.34,0.030)$ & $1.77(0.96$ to $3.28,0.068)$ \\
\hline \multicolumn{5}{|c|}{ Composite MMAS-8 (N=321, 183 responses missing)† (adherent+stopped+changed) } \\
\hline Normal practice & $108 / 167(64.7)$ & 1.00 & 1.00 & 1.00 \\
\hline NMS & $116 / 154(75.3), 0.038$ & $1.67(1.03$ to $2.71,0.039)$ & $1.78(1.06$ to $3.00,0.029)$ & $1.81(1.07$ to $3.05,0.027)$ \\
\hline
\end{tabular}


full sample (Model 3), the OR (95\% CI) was 1.62 (1.04 to $2.53, \mathrm{p}=0.032$ ) in favour of NMS.

MMAS-8 and composite outcome

By Week 10, across both groups, there were 37 $(8.2 \%)$ reports of patients with changed medicines and $31(6.9 \%)$ reports of patients with stopped medicines. Amlodipine was most often cited as the medicine that was stopped or changed.

When the ITT analysis was carried out using the composite outcome, or MMAS- 8 to measure adherence, similar results to the primary analysis were obtained.

Exploratory analysis suggested that effect size was similar across the four therapeutic areas, although none of the findings were statistically significant (see online supplementary appendix table 4).

\section{Effect of NMS on other outcomes}

No change in beliefs about medicines or health status was observed (see online supplementary appendix tables 5 and 6).

Further exploration of contributors to the effectiveness of the NMS suggested that pharmacy characteristics (ownership and location) rather than patient characteristics had an impact (see online supplementary appendix table 7). The likelihood of being more adherent following an NMS consultation is almost double if conducted by a small multiple compared with an independent (OR 1.00 vs $0.57, \mathrm{p}=0.042$ ). However, as one small multiple recruited 99 patients, this may have influenced the results unduly. Removal of this subset of patients did not affect the effect size. The data for large multiples and supermarkets did not suggest any difference.

Patients most frequently attributed factors such as forgetting, experiencing side effects and their beliefs about their prescribed medicine to their non-adherent behaviour (see online supplementary appendix table 8).

\section{Effect of NMS on costs}

Mean (median, range) total NHS cost for patients in normal practice and NMS are $£ 261$ ( $£ 121, £ 0-1669)$, and $£ 239$ ( $£ 135, £ 25-1483$ ), respectively (see online supplementary appendix table 9). The NMS intervention incurred slightly lower NHS cost, albeit statistically non-significant, for: $£ 21$ (95\% CI $-£ 59$ to $£ 150$, $\mathrm{p}=0.1281$ ).

No reports of patient harm due to the intervention or study participation were reported.

\section{DISCUSSION}

The NMS significantly increased the proportion of patients reporting adherence to their new medicine by $10.2-70.7 \%$, compared with normal practice, $60.5 \%$. These results were consistent across two adherence measures and taking account of confounders and missing data. The cost to the NHS of paying community pharmacists to deliver NMS was absorbed by small reductions in other NHS contact-related costs.

Effect size appeared to be constant across disease areas. The proportion of non-adherent patients in each therapeutic group of our sample varies between disease, which is widely known ${ }^{43}$ and the proportions reflect those in the literature. ${ }^{4-50}$ This consistent effect supports the theoretical approach of the intervention to allow patient concerns to take priority. This supports the consideration of offering the service in diseases currently outside the remit of the current NMS specification, including mental health. The lack of consistent direction of effect with increased age, ${ }^{5152} \operatorname{sex}^{12}$ and deprivation status ${ }^{12}{ }^{24}$ has been previously observed.

Pharmacy ownership and location may affect the effectiveness of NMS but our data are inconclusive and further work is needed to establish their validity.

\section{Strengths and limitations}

This was a pragmatic trial of an existing commissioned service to make sure that results were as generalisable to real-world practice as possible, and was also a methodologically rigorous trial, such that effect sizes reported can be considered internally robust. Sites were closely followed up and supported in running the trial face-to-face and over the telephone. Where recruitment was particularly hampered, most common reasons were NMS conducted in languages other than English; and pharmacists and patients with time constraints.

A cluster RCT design was rejected as this would mean a set of pharmacies would not be able to participate in NMS and this was unlikely to be acceptable to pharmacies, which would lose income and competitive advantage. A quasi-experiment (comparing pharmacies providing NMS with those not providing NMS) was rejected because of possible differences in the two populations of pharmacies. The research team would have had no control over subsequent decisions of pharmacies to start providing NMS, so would have potentially lost substantial numbers of the control group. Patient-level randomisation allowed for control of pharmacy characteristics. Contamination between NMS and normal practice patients from the same pharmacy was very unlikely due to the low frequency of NMS-eligible patients. The difference between NMS and normal practice is the presence or absence of two one-to-one consultations, meaning that the delivery of one arm is unlikely to be affected by the delivery of the other arm.

The evaluation was of the implementation of a commissioned service in the real-world setting so the research team did not standardise intervention delivery. To retain the pragmatic design of the study it was not practicable to quality assure each episode in situ. 
Qualitative work has investigated the variability of intervention delivery. ${ }^{22}$

There is no gold standard for measuring patients' adherence. In this study there were few measurement options. Direct measures such as measuring plasma levels are invasive and impractical, and indirect measures such as 'pill counts' are open to bias. Prescription-filling ${ }^{53}$ was not an option for routine monitoring in England due to lack of interoperability between community pharmacy and GP systems and patients may use more than one pharmacy. It should be remembered that the most commonly used objective adherence measure, prescription-filling, has the limitation that it assumes that a prescription filled is actually taken by the patient.

Recommended practice is that more than one adherence measure is employed in a study to provide some assessment of validity. ${ }^{1}$ In this study, we chose two self-report measures. Patient-reported measures of behaviour and outcome are important. ${ }^{54}$ Self-report tends to return higher rates of medication adherence $(+15 \%)$ than some objective measures, due to social desirability and memory bias. However, when patients report they have been non-adherent, these accounts are generally accurate,${ }^{55}$ and patientreported adherence correlates with objective clinical measures. ${ }^{56}$

It is likely that adherence was overestimated by patients in both arms of the RCT. Patients in the NMS arm could have felt under more pressure to report adherence to their medicine. Reporting bias was minimised through confidential interview, ${ }^{57}$ normalising non-adherence by recognising the challenges of taking regular medications, avoiding leading questions and asking about missed doses in the week prior to data collection rather than 1 month or year. ${ }^{58}$

Patients' adherence was assessed in the previous 7 days at 10 weeks after the intervention, rather than as continuum or over the longer term, so it provides a snapshot of adherence. NMS is designed to improve adherence early in the therapy, which it has been demonstrated to achieve. NMS is not intended to be a one-off intervention that is isolated from care pathways, but to be integrated into longer-term medicines optimisation strategies.

Patient outcomes including hospital admissions and premature death are improved with increased medicines adherence. ${ }^{59-62}$ Specific disease pathology and pharmacology of the medicine moderate the link between non-adherence and outcomes. For example, the consequences of non-adherence in epilepsy become apparent quickly, whereas in hypertension, non-adherence may not cause morbidity for many years. Appropriate time intervals after non-adherence begins need to be incorporated into any appraisals. To know that patient outcomes will improve as a result of NMS requires a sufficiently powered study, long enough to assess impact on patient outcome, with associated higher research costs, maybe not delivering timely evidence for policy decision-making.

\section{Comparison with other studies}

Community pharmacists can improve adherence to medication, ${ }^{63}$ and improve outcomes. ${ }^{64}$ The effectiveness in this study is similar to the effectiveness of more complex adherence interventions, and could be more effective if recommendations made here are followed. It should also be remembered that, given the high proportion of patients taking medicines, relatively small increases in percentages can affect large numbers of patients. The intervention developed by Barber $e t$ al, and the basis for design and implementation of the NMS, produced an absolute 10\% increase in adherence, similar to NMS. ${ }^{15}$ Interventions to improve adherence are often multifaceted, without clear rationale for each part. ${ }^{65}$ Simpler designs such as the NMS are needed. Telephone follow-up is a flexible and relatively low-cost approach. An RCT of telephone follow-up for patients prescribed a statin for the first time who hadn't filled the initial prescription showed an increase in adherence from $26 \%$ to $42.3 \%(\mathrm{p}=0.001) .{ }^{66}$ This and our study suggest that a simple but theory-driven intervention can be effective.

\section{Implications for clinicians and policy-makers}

The NMS is an initiative that encapsulates the priorities and aims of current policies around medicines optimisation, helping patients and payers. ${ }^{67}$ However, the future success of the NMS relies partly on its integration into primary care provision. Viewing medicines management as an integral part of providing care for people with long-term conditions provides support for the continued used of the NMS. ${ }^{68}$ An environment enabling a triangular model of relationship and engagement between the patient, GP and pharmacist is desirable if optimal medicines use is to be realised. Factors including insufficient integration, underdeveloped relationships between a patient's pharmacist and GP, relatively inaccessible patient records, poorly devised strategies for targeting services and the unwillingness by some pharmacists to offer NMS have hampered the implementation of community pharmacy-led clinical services. ${ }^{69} 70$

Facilitation is needed at local levels, such as tailoring information technology systems to help foster local relationships. This requires decision-makers at a higher level to make funding available. Electronic integration would allow routine use of prescriptionfilling to assess adherence, a proxy measure associated with limitations, but easier to collect routinely than self-report if integrated systems exist. Finally, feedback pathways which incorporate mentoring and opportunities for peer review are recommended for practitioners to enhance their own skills. 
Author affiliations

${ }^{1}$ School of Pharmacy, University of Nottingham, Nottingham, UK

${ }^{2}$ Division of Social Research in Medicines and Health, University of Nottingham School of Pharmacy, Nottingham, UK ${ }^{3}$ Department of Policy and Research, The Company Chemists' Association, London, UK

${ }^{4}$ Health Foundation, London, UK

${ }^{5}$ School of Medicine, University of Nottingham, Nottingham, UK

${ }^{6}$ School of Pharmacy, University of Nottingham, Nottingham,

UK

${ }^{7}$ Nottingham University Business School, University of

Nottingham, Nottingham, UK

${ }^{8}$ Division of Primary Care, School of Community Health

Sciences, Primary Care, University of Nottingham, Nottingham, UK

Acknowledgements Professor D E Morisky, UCLA School of Public Health, has granted copyright permission to use the MMAS-8 adherence tool.

Contributors NMS study conception and design: RAE, MB, NB, JW, AJA, RLM and AC; Literature search RAE, MB and $\mathrm{NB}$; NMS trial design, operationalisation and management: RAE, MB, AJA, N-ES, JD and AL; Service liaison: MB, N-ES, JD and AL; Data collection: N-ES, AL, JD and CC; Data processing: MB, N-ES, CC and GG; Statistical analysis: RLM and LT; Interpretation, paper drafting: RAE, MB, N-ES, JD, NB, RLM, LT, JW, AJA, AC, GG, CC and AL. All authors contributed to editing and approved the final text. All authors had full access to data and take responsibility for its integrity and the accuracy of the analysis.

Funding Department of Health Policy Research Programme (grant number PRP 029/0124).

Disclaimer The views expressed in this article are those of the author(s) and not necessarily those of the NHS, the NIHR or the Department of Health. The funder provided financial support for the study but had no role in the study design, data analysis and drafting of reports. The researchers were independent of the funder.

Competing interests None declared.

Ethics approval National Research Ethics Service (NRES) West Midlands-Black Country Research Ethics Committee (12/WM/ 0096) 2 May 2012.

Provenance and peer review Not commissioned; externally peer reviewed.

Open Access This is an Open Access article distributed in accordance with the Creative Commons Attribution Non Commercial (CC BY-NC 4.0) license, which permits others to distribute, remix, adapt, build upon this work noncommercially, and license their derivative works on differen terms, provided the original work is properly cited and the use is non-commercial. See: http://creativecommons.org/licenses/by$\mathrm{nc} / 4.0 /$

\section{REFERENCES}

1 Horne R, Weinman J, Barber N, et al. Concordance, adherence and compliance in medicine taking. Report for the National Co-ordinating Centre for NHS Service Delivery and Organisation R \& D (NCCSDO). December 2005. http://www.netscc.ac.uk/hsdr/files/project/SDO_FR_08-1412076_V01.pdf

2 Marsden E, Cubbin I, McAlavey A. An investigation into how poor compliance traditionally associated with corticosteroid therapy in asthma and chronic obstructive pulmonary disease can be improved to enhance long-term management and patient care. Int J Pharm Pract 2009;17(S2): B55-6.
3 Cerveri I, Locatelli F, Zoia MC, et al. International variations in asthma treatment compliance: the results of the European Community Respiratory Health Survey (ECRHS). Eur Respir J 1999;14:288-94.

4 Llorca PM. Patient compliance in schizophrenia and the impact on patient outcome. Psychiatr Res 2008;161:235-47.

5 Ereshefsky L, Saragoussi D, Despiégel N, et al. The 6-month persistence on SSRIs and associated economic burden. J Med Econ 2010;13:527-36.

6 Ho PM, Rumsfeld JS, Masoudi FA, et al. Effect of medication nonadherence on hospitalization and mortality among patients with diabetes mellitus. Arch Intern Med 2006;166:1836-41.

7 Ho PM, Spertus JA, Masoudi FA, et al. Impact of medication therapy discontinuation on mortality after myocardial infarction. Arch Intern Med 2006;166:1842-7.

8 Vestbo J, Anderson JA, Calverley PM, et al. Adherence to inhaled therapy, mortality and hospital admission in COPD. Thorax 2009;64:939-43.

9 IMS Institute for Healthcare Informatics. Advancing the responsible use of medicines: applying levers for change. Parsipanny, USA: IMS Health, 2012.

10 Trueman P, Lowson K, Blighe A, et al. Evaluation of the Scale, Causes and Costs of Waste Medicines. 2010. http://www. pharmacy.ac.uk/fileadmin/documents/News/Evaluation_of_ NHS Medicines Waste web publication version.pdf

11 Nieuwlaat R, Wilczynski N, Navarro T, et al. Interventions for enhancing medication adherence. Cochrane Database Syst Rev 2014;(11):CD000011.

12 Elliott RA. Strategies for improving poor adherence to medication to optimize rheumatoid arthritis disease management. Dis Manage Health Outcomes 2008;16:13-29.

13 Barber N, Parsons J, Clifford S, et al. Patients' problems with new medication for chronic conditions. Qual Saf Health Care 2004;13:172-5.

14 Leventhal H, Cameron LD. Behavioral theories and the problem of compliance. Patient Educ Couns 1987;10:117-38.

15 Clifford S, Barber N, Elliott R, et al. Patient-centred advice is effective in improving adherence to medicines. Pharm World Sci 2006;28:165-70.

16 Elliott RA, Clifford S, Barber N, et al. The cost effectiveness of a pharmacy advisory service to improve adherence to medicines. Pharm World Sci 2008;30:17-23.

17 Department of Health. Pharmacy in England: Building on strengths—delivering the future. 2008. http://www.dh.gov.uk/ en/Publicationsandstatistics/Publications/PublicationsPolicy AndGuidance/DH 083815

18 Pharmaceutical Services Negotiating Committee. New Medicines Service. Secondary New Medicines Service. 2011. http://www.psnc.org.uk/pages/nms.html

19 NHS Business Services Authority. Complete New Medicines Service (NMS) data. London: NHSBSA, 2014.

20 Schulz KF, Altman DG, Moher D. CONSORT 2010 Statement: updated guidelines for reporting parallel group randomised trials. BMJ 2010;340:c332.

21 Boyd M, Waring J, Barber N, et al. Protocol for the New Medicine Service Study: a randomized controlled trial and economic evaluation with qualitative appraisal comparing the effectiveness and cost effectiveness of the New Medicine Service in community pharmacies in England. Trials 2013;14:411.

22 Elliott R, Boyd M, Waring J, et al. Understanding and Appraising the New Medicines Service in the NHS in England (029/0124)' A randomised controlled trial and economic 
evaluation with qualitative appraisal comparing the effectiveness and cost effectiveness of the New Medicine Service in community pharmacies in England. University of Nottingham, 2014.

23 Inc. SI. SAS Version 9.3(TS1M1). Cray, NC, USA: SAS Institute Inc., 2011.

24 Elliott RA. Poor adherence to anti-inflammatory medication in asthma: reasons, challenges, and strategies for improved disease management. Dis Manage Health Outcomes 2006;14:223-33.

25 Pharmaceutical Services Negotiating Committee, NHS Employers. NHS Community Pharmacy Contractual Framework 2011/12 Service Developments-Latest Information. August 2011. http://www.psnc.org.uk/data/files/ PharmacyContract/Contract_changes_2011/summary_of_cpcf_ changes_may_2011.pdf (accessed 4/8/2011).

26 Morisky DE, Ang A, Krousel-Wood M, et al. Predictive validity of a medication adherence measure in an outpatient setting. J Clin Hypertens 2008;10:348-54.

27 Euroqol Group. Measuring Self-Reported Population Health-An International Perspective based on EQ-5D. Secondary Measuring Self-Reported Population Health-An International Perspective based on EQ-5D. 2008. http://www. euroqol.org/fileadmin/user_upload/Documenten/PDF/Books/ Measuring_Self-Reported_Population_Health_-_An_ International_Perspective_based_on_EQ-5D.pdf

28 Horne R, Weinman J, Hankins M. The beliefs about medicines questionnaire: the development of and evaluation of a new method for assessing the cognitive representation of medication. Psychol Health 1999;14:1-24.

29 National Health Service Executive. NHS Reference Costs 201213. Secondary NHS Reference Costs 2012-13, Department of Health, London, 2013.

30 Personal Social Services Research Unit. Unit Costs of Health and Social Care 2013. Compiled by Lesley Curtis. 2013 Pub: Personal Social Services Research Unit, The University of Kent.

31 Briggs A, Gray A. The distribution of health care costs and their statistical analysis for economic evaluation.J Health Serv Res Policy 1998;3:233-45.

32 Hollis S, Campbell F. What is meant by intention to treat analysis? Survey of published randomised controlled trials. BMJ 1999;319:670-4.

33 Shih WJ. Problems in dealing with missing data and informative censoring in clinical trials. Curr Control Trials Cardiovasc Med 2002;3:4.

34 Royston P. Multiple imputation of missing values: further update of ICE, with emphasis on categorical variables. Stata J 2009;9:466-77.

35 Carlin JB, Galati JC, Royston P. A new framework for managing and analysing multiply imputed data sets in Stata. Stata J 2008;8:49-67.

36 Zwger SL, Liang KY. Longitudinal data analysis using generalized linear models. Biometrica 1986;73:13-22.

37 Fitzmaurice GM, Laird NM, Ware JH. Applied Longitudinal Analysis. New Jersey: Wiley, 2004.

38 Assmann SF, Pocock SJ, Enos LE, et al. Subgroup analysis and other (mis)uses of baseline data in clinical trials. Lancet 2000;355:1064-9.

39 IBM Corp. IBM SPSS Statistics for Windows. Version 20.0. Armonk, NY: IBM Corp, 2011.

40 StataCorp LP. Stata data analysis and statistical Software. Special Edition Release 10.1 edition, STATA Press, 2008.
41 Office for National Statistics. Enumeration Postcodes (2011) to output areas (2011) to lower layer super output areas (2011) to middle layer super output areas (2011) to local authority districts (2011) E+W Lookup, 2011.

42 PricewaterhouseCoopers LLP. Cost of Service Inquiry for Community Pharmacy Report by PwC. London: PriceWaterhouseCooper, 2011.

43 DiMatteo MR. Variations in patients' adherence to medical recommendations: a quantitative review of 50 years of research. [see comment]. Med Care 2004;42:200-9.

44 Vrijens B, Vincze G, Kristanto P, et al. Adherence to prescribed antihypertensive drug treatments: longitudinal study of electronically compiled dosing histories. BMJ 2008;336: 1114-17.

45 Caro JJ, Salas M, Speckman JL, et al. Persistence with treatment for hypertension in actual practice. CMAJ 1999;160:31-7.

46 Garg VK, Bidani R, Rich EP, et al. Asthma patients' knowledge, perception, and adherence to the asthma guidelines. Journal of Asthma 2005;42:633-8.

47 Cramer JA. A Systematic Review of Adherence With Medications for Diabetes. Diabetes Care 2004;27:1218-24.

48 Shemesh E, Yehuda R, Milo O, et al. Posttraumatic stress, nonadherence, and adverse outcome in survivors of a myocardial infarction. Psychosom Med 2004;66: 521-6.

49 Simpson E, Beck C, Richard H, et al. Drug prescriptions after acute myocardial infarction: Dosage, compliance, and persistence. Am Heart J 2003;145:438-44.

50 Quilici J, Fugon L, Beguin S, et al. Effect of motivational mobile phone short message service on aspirin adherence after coronary stenting for acute coronary syndrome. Int J Cardiol 2013;168:568-9.

51 Vik SA, Maxwell CJ, Hogan DB. Measurement, correlates and health outcomes of medication adherence among seniors. Ann Pharmacother 2004;38:303-12.

52 Kazis LE, Friedman RH. Improving medication compliance in the elderly. Strategies for the health care provider. J Am Geriatr Soc 1988;36:1161-2.

53 Shi L, Liu J, Koleva Y, et al. Concordance of adherence measurement using self-reported adherence questionnaires and medication monitoring devices. Pharmacoeconomics 2010;28:1097-107.

54 Black N. Patient reported outcome measures could help transform healthcare. BMJ 2013;346:f167.

55 Choo PW, Rand CS, Inui TS, et al. Validation of patient reports, automated pharmacy records, and pill counts with electronic monitoring of adherence to antihypertensive therapy. Med Care 1999;37:846-57.

56 Murri R, Ammassari A, Gallicano K, et al. Patient-Reported Nonadherence to HAART Is Related to Protease Inhibitor Levels. J Acquir Immune Defic Syndr 2000;24:123-8.

57 Butler JA, Peveler RC, Roderick P, et al. Measuring compliance with drug regimens after renal transplantation: comparison of self-report and clinician rating with electronic monitoring. Transplantation 2004;77:786-9.

58 Lehmann A, Aslani P, Ahmed R, et al. Assessing medication adherence: options to consider. Int J Clin Pharma 2014;36:55-69.

59 Dartnell JGA, Anderson RP, Chohan V, et al. Hospitalisation for adverse events related to drug therapy: incidence, avoidability and costs. Med J Aust 1996;164:659-62. 
60 Psaty BM, Koepsell TD, Wagner EH, et al. The relative risk of incident coronary heart disease associated with recently stopping the use of $\beta$-blockers. J Am Med Assoc 1990;263:1653-7.

61 Weiden PJ, Olfson M. Cost of relapse in schizophrenia. Schizophr Bull 1995;21:419-29.

62 Lau DT, Nau DP. Oral antihypoglycaemic medication nonadherence and subsequent hospitalization among individuals with Type 2 diabetes. Diabetes Care 2004;27:2149-53.

63 Fikri-Benbrahim N, Faus MJ, Martínez-Martínez F, et al. Impact of a community pharmacists' hypertension-care service on medication adherence. The AFenPA study. Res Social Adm Pharm 2013;9:797-805.

64 Kjeldsen LJ, Bjerrum L, Dam P, et al. Safe and effective use of medicines for patients with type 2 diabetes-A randomized controlled trial of two interventions delivered by local pharmacies. Res Social Adm Pharm 2015;11:47-62.
65 Haynes RB, Ackloo E, Sahota N, et al. Interventions for enhancing medication adherence (Review). Cochrane Database Syst Rev 2008;(2):CD000011.

66 Derose SF, Green K, Marrett E, et al. AUtomated outreach to increase primary adherence to cholesterol-lowering medications. JAMA Intern Med 2013;173:38-43.

67 Royal Pharmaceutical Society. Medicines optimisation. London: Royal Pharmaceutical Society, 2013.

68 The Kings Fund. Polypharmacy and medicines optimisation: making it safe and sound. London: The King's Fund, 2013.

69 Blenkinsopp A, Bond CM. The potential and pitfalls of medicine management: What have we learned so far? Dis Manag Health Outcomes 2008;16:79-86.

70 Mossialos E, Courtin E, Naci H, et al. From “retailers" to health care providers: Transforming the role of community pharmacists in chronic disease management. Health Policy 2015;119:628-39. 